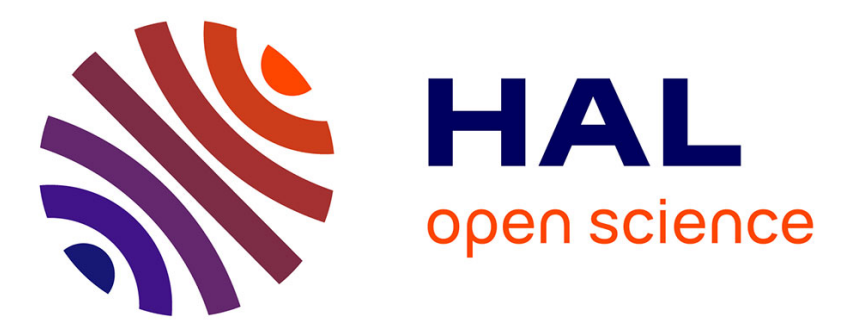

\title{
Space charge criteria in the assessment of insulation materials for HVDC
}

Thi Thu Nga Vu, G. Teyssedre, Séverine Le Roy, Christian Laurent

\section{To cite this version:}

Thi Thu Nga Vu, G. Teyssedre, Séverine Le Roy, Christian Laurent. Space charge criteria in the assessment of insulation materials for HVDC. IEEE Transactions on Dielectrics and Electrical Insulation, 2017, 24 (3), pp.1405-1415. 10.1109/TDEI.2017.006059 . hal-03169885

\section{HAL Id: hal-03169885 \\ https://hal.science/hal-03169885}

Submitted on 21 Nov 2021

HAL is a multi-disciplinary open access archive for the deposit and dissemination of scientific research documents, whether they are published or not. The documents may come from teaching and research institutions in France or abroad, or from public or private research centers.
L'archive ouverte pluridisciplinaire HAL, est destinée au dépôt et à la diffusion de documents scientifiques de niveau recherche, publiés ou non, émanant des établissements d'enseignement et de recherche français ou étrangers, des laboratoires publics ou privés. 


\title{
Space Charge Criteria in the Assessment of Insulation Materials for HVDC
}

\author{
T.T.N. Vu ${ }^{1,2}$, G. Teyssedre ${ }^{1}$, S. Le Roy ${ }^{1}$ and C. Laurent ${ }^{1}$ \\ ${ }^{1}$ LAPLACE (Laboratoire Plasma et Conversion d'Energie), Université de Toulouse, \\ CNRS, INPT, UPS, Bat 3R3, 118 route de Narbonne, F-31062 Toulouse Cedex 9, France \\ ${ }^{2}$ Electric Power University, 235 Hoang Quoc Viet, Hanoi, Vietnam.
}

\begin{abstract}
The purpose of this work is to present and to discuss a methodology for the assessment of materials intended to be used as insulation in HVDC cables, particularly as regards the evaluation of the effects of material formulation on space charge accumulation within the insulation. Sample design, testing method and protocol and criteria used for the material evaluation are specifically considered. The criteria being put forward are based on available models of insulation life vs. stress with consideration of polarity reversal effects. It is shown through several examples using low density polyethylene and crosslinked polyethylene materials that criteria such as the Field Enhancement Factor and the space-averaged residual charge density are indeed sensitive to material formulation and especially to the presence of crosslinking by-products. When using a crosslinking process that does not produce residues, the material tends to behave like low density polyethylene regarding space charge features. Finally, the question of the representativeness of tests performed on flat specimens vs. model or full cables is discussed.
\end{abstract}

Index Terms - HVDC insulation, space charge, materials assessment, LDPE, XLPE.

\section{INTRODUCTION}

THE number of HVDC links installed and in projects is experiencing an unprecedented growth due to the superiority of DC over the traditional HVAC energy transport with latest developments in converter technologies [1,2]. Further, the development of cable manufacturing with synthetic insulations is encouraged, as it provides advantages in terms of cost, operating temperature, the risk of pollution or maintenance in comparison to impregnated paper-based insulation [3]. These evolutions of HVDC energy networks have impacts on insulating materials: design rules as well as material quality assessment criteria are not necessarily anymore the same as with HVAC systems $[4,5]$. Material conductivity, the nonlinear response in field and space charge effects are among key features for HVDC with challenges for full control and modelling. Indeed, the switch from a capacitive-shaped to a resistive-shaped field distribution on going from $\mathrm{AC}$ to $\mathrm{DC}$ faces the much stronger dependence of conductivity than permittivity on temperature, field, and even material nature. Impact on design can be viewed at least in three practical situations: in HVDC cables under temperature gradient, in piece parts with materials of different nature, and in designs imposing a large geometrical field enhancement.

In cables under thermal gradient, the consequence is a reduction of the field at the inner semiconductor (semicon) of the cable and a strengthening of the field to the outer one [6].
So, this could be viewed as a trend to field homogenization in the bulk. However, depending on the actual field and temperature dependencies of the conductivity, a stress inversion phenomenon can be obtained, i.e. field being maximum at outer semicon [7], with consequences on accessories reliability. Therefore, from the standpoint of field homogenization, the targeted properties for materials would be a relatively low activation energy for conductivity (i.e. weak dependence of conductivity on temperature) and effective nonlinear conductivity with field [7].

In association of dielectrics, the stress can move from one material to the other, with changing field or temperature and experimental measurements on field distribution on flat specimen are consistent with field distribution expected from conductivity data [8]. The association of insulating materials of different nature, as in joints and cable terminations [9], coupled to these non-linear effects and to thermal gradients, may make the prediction of field distributions in service conditions substantially more difficult. Out of the cable applications, the association of solid and gaseous insulations as with spacers in gas-insulated systems constitutes another situation where it is impossible to anticipate which of the three field distribution states: capacitive, resistive or transient, will be most critical [10].

Finally, in HVDC cables with thick insulations, thermal runaway in the insulation could eventually occur at high 
temperature: the resistivity of the material must be sufficiently high to avoid these effects $[11,12]$.

All the features addressed above can in principle be handled at the design step if the materials properties are known at any field/temperature. Here much could be said about the appropriate determination method of conductivity, as most often it is extremely hypothetical to obtain a steady state DC current and the measurement can be sensitive to the electrodes being used and do not necessarily represent intrinsic properties of materials $[5,13]$.

The other main properties to be assessed for application of insulating materials to HVDC is that concerning space charge features, which are suspected to lead to the reduction of the cable performance and/or lifetime. A direct effect of the space charge is the distortion of the electric field distribution in the insulation, therefore hampering the modelling of field distribution that can be done based on conductivity data. This concerns the generation and storage of charges into the insulation, in principle by process other than conductivity gradient: the conductivity gradient found in cables under thermal gradient on its own generates a space charge [14] and early field distortions found in HVDC cables have been interpreted by McAllister et al. [15] as a consequence of nonuniform conductivity. A second harmful consequence of space charges is the possibility to trigger ageing phenomena into the insulation though potential or kinetic energy associated with the release of these charges.

The propensity of insulations made for HVAC cables, especially crosslinked polyethylene, to generate space charges has led to the development of new generation of materials providing fewer charges, with emphasis on the improved physical and chemical cleanliness of materials [12].

Whatever their origin, depending on their position in the bulk of the insulation, on their nature (polarity, homo- vs. hetero-charges, etc.), the consequences of the presence of charges may not be the same. Besides, the space charge distribution patterns can be substantially different from one material to the other and therefore, there is a need for reducing the amount of data available into relevant quantities for materials assessment. Space charges measurement in dielectrics has become rather common practice for investigating charge accumulation processes under electrical stress. A wealth of measurement system exists with their respective merit in terms of sensitivity, sample geometry, measurement dynamics, etc. They represent interesting tools in the perspective of optimizing semicon / insulation materials formulation intended to HVDC cables provided adequate criteria are identified. The aim of the present work is to present a methodology for cable materials screening, including:

- Manufacturing of plaque samples;

- Field and temperature testing conditions;

- Measurement technique;

- Criteria for materials assessment.

In a first section of this contribution, we present the approach we have developed for space charge criteria [16], based on models for materials endurance under DC stress. The analysis provides figures for the relative merit of materials for the purpose of materials screening. In a second section, we show how the so-developed analysis can be implemented on polyethylene materials of different nature.

\section{ASSESSMENT METHODOLOGY}

\subsection{LIFE MODELS VS. SPACE CHARGE \\ 2.1.1 WITHOUT POLARITY INVERSION}

When a cable is intended to work with Voltage Source Converters - VSC system, the inversion of power flux is achieved by changing the current direction without inverting the voltage polarity. In that case, the insulation life is generally estimated through the well-known Inverse Power Law - a semi-empirical relationship giving the time to breakdown as a function of the maximum stress level through the insulation:

$$
L=C .\left(\frac{1}{F_{\max }}\right)^{N}
$$

where $F_{\text {max }}$ accounts for the maximum electrical stress through the insulating material, $N$ is the aging parameter also known as the Voltage Endurance Coefficient (VEC) and C is a constant.

Space charge accumulation under DC stress leads to local field enhancement within the insulating material hence decreasing the time to breakdown. Furthermore, it has been pointed out that space charge is likely to take part in the ageing process through the modification of the material structure [17] and may act to increase the VEC. Considering a value of VEC of 10, in accordance with the Cigré recommendations for $\mathrm{HV}$ extruded cables [18], a field enhancement of $10 \%$ of the Laplacian field leads to a life reduction by a factor about 3 . For non-optimized insulation, the amount of space charge (and thus the field distortion factor) mostly increases with the applied voltage. In order to keep an acceptable cable life, the design stress has then to be limited reducing thereby the power transmission efficiency (power per unit of the cable weight).

\subsubsection{WITH POLARITY INVERSION}

Line Commutated Converters -LCC cable system requires voltage polarity reversals for changing the power flux. Hence cables have to be designed to withstand such kind of stress. In that case, it has been demonstrated [19] through accelerated life tests coupled to space charge measurements that the insulation life depends not only on the electrical stress level but also on different parameters related to the charge accumulation among which the quantity of charge $\left(Q_{M}\right)$ obtained after a polarization procedure under an applied field $F_{a p p}$, the charge depletion rate during depolarization (s) and the frequency of polarity inversion $(f)$. According to the model proposed by Cavallini et al [20], the ratio between life with and without voltage inversion is given by:

$$
\frac{L_{I}}{L}=\frac{1}{1+K \cdot s^{-a_{1}} Q\left(F_{a p p}\right) \cdot f^{a_{2}}}
$$

where $K, a_{1}$ and $a_{2}$ are correlation coefficients.

According to the above relationship, it can be emphasized that the insulation life decreases with the frequency of 
inversion and the amount of trapped charge $\left(Q_{M}\right)$. For polymeric materials, $Q_{M}$ is generally assumed to evolve as a power function of the applied field $F_{a p p}[19,20]$ for electrical stresses above the ohmic regime, namely $Q_{M} \propto F_{a p p}{ }^{b}$, with $b$ characterizing the charge accumulation rate versus the applied stress.

It is worth mentioning that, according to the model, the insulation life in the presence of inversions $\left(L_{I}\right)$ decreases inversely with the charge depletion rate. It means that in the presence of inversion, the material should be able to expel trapped charges as fast as possible during short-circuit. As a consequence, the presence of deep traps within the insulating material introduced by chemical additives may be harmful with regard to the material endurance.

\subsubsection{ASSESSMENT BASED ON SHORT TERM TESTS}

According to the model presented above, qualification of additives relevant to crosslinked materials (antioxidants, crosslinking agents, etc.) may be performed by deriving relevant parameters from space charge measurements. For a given case study (i.e. XLPE), it can be assumed that the correlation coefficients $\left(\mathrm{K}, a_{1}\right.$ and $\left.a_{2}\right)$ involved in the expression of the insulation life $\left(L_{I}\right)$ are not modified by changing the nature of additives and only the parameters related to space charges that are the field reinforcement factor, the trapped charges density and the depletion rate during voltoff are modified. These parameters may be derived using short term testing under proper conditions of electrical stress and temperature. Moreover, when several formulations are investigated, quality comparison could be done on the basis of space charge parameters assuming that the best formulation is the one which exhibits an optimized set of properties, say the lowest amount of space charge (implying in general weak field amplification) and a high rate of charge release during voltoff.

\subsection{TEST CONDITIONS}

\subsubsection{SPACE CHARGE MEASUREMENT TECHNIQUE}

For the current analysis, we have selected the pulsed electro-acoustic-PEA- method for space charge measurement [21] first because of its simplicity of use and second because of its flexibility insofar as a wide range of material thicknesses can be measured, typically from $100 \mu \mathrm{m}$ to several millimeters for XLPE materials. This can be achieved by adapting the device characteristics such as the pulse width or the piezoelectric sensor thickness. Another advantage of the PEA method is that measurements are easy to perform both in Volton and Volt-off because of the nature of the excitation (electrical pulse) and through the use of a decoupling capacitor. The PEA system also provides an excellent time resolution (typically 1 profile/s for plaque specimen) and therefore enables to detect fast time-varying phenomena such as the so-called fast charge packets [22].

The method can also be adapted to coaxial geometry which is advantageous for taking into account the thermal gradient existing in cables and to fit to the cylindrical geometry of real cables. However, signal processing is somewhat trickier due to the impact of thermal gradient and the need to account for the cylindrical geometry and the attenuation of the acoustic waves in the deconvolution of raw PEA signal [23, 24].

\subsubsection{SAMPLES PROCESSING}

Rough products were LDPE - low density polyethylene and semiconducting materials- SC, in the form of granules, both being cross-linkable, i.e. containing peroxide. Plaques of LDPE and SC materials were processed by press-molding at $120{ }^{\circ} \mathrm{C}$. Then, disks of SC material, $12 \mathrm{~mm}$ in diameter, were cut. The final samples were obtained, with structure described in Figure 1, by cross-linking the 3 layers altogether at $180{ }^{\circ} \mathrm{C}$ for 15 min under a press. The upper semiconducting electrode (in contact with the PEA electrode to which voltage is applied) is chosen thicker (typically $600 \mu \mathrm{m}$ ) than the lower one (in contact with the PEA electrode connected to the acoustic sensor) to attenuate possible reflection of the acoustic waves that may occur at the interfaces between the sample and the metallic electrodes of the PEA cell due to acoustic impedance mismatch between these materials. The lower semiconducting electrode is chosen as thin as possible (typically $200 \mu \mathrm{m}$ ) to keep a reasonable spatial resolution. The insulation layer was limited to $500 \mu \mathrm{m}$ for the purpose of reaching high level of electrical stress (up to $40 \mathrm{kV} / \mathrm{mm}$ ) taking into account the maximum voltage than can stand the PEA test cell $(30 \mathrm{kV})$. This is also advantageous because it reduces attenuation and dispersion of the acoustic waves.

The picture of Figure 2 shows an example of cross-section of such samples (showing distinctly the three different layers). Typical sample geometry is $200 \mu \mathrm{m} / 500 \mu \mathrm{m} / 600 \mu \mathrm{m}$ for SC/Insulation/SC structures.

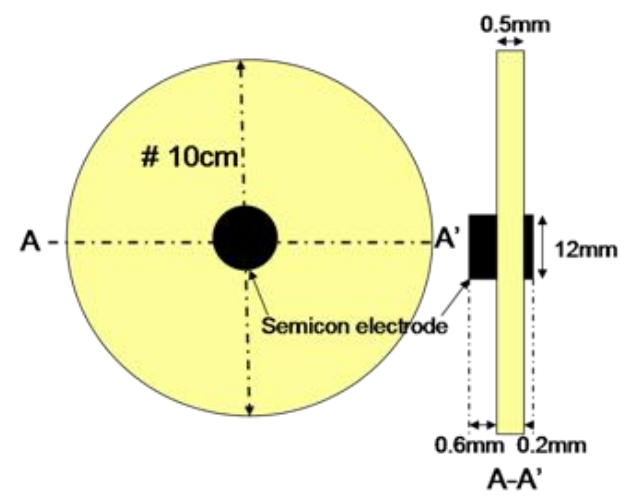

Figure 1. Typical geometry of plaque samples.

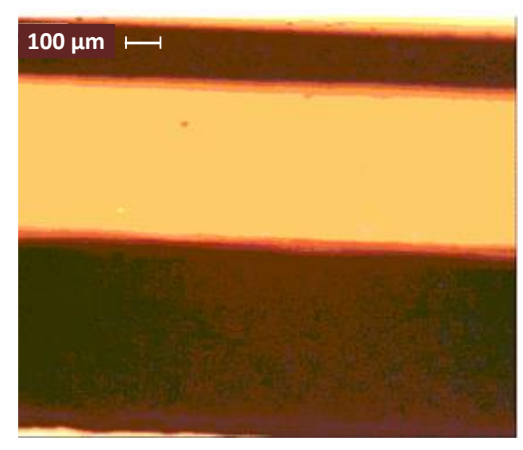

Figure 2. Cross-section of a SC/XLPE/SC sandwich. 
For evaluating the impact of insulating material formulation (base resin, antioxidants or different cross-linking agents), gold electrodes were used instead of semicon. In that case, electrodes are deposited onto the insulating samples by sputtering of a gold target. Deposited gold layers have to be thick enough (typically thicker than $30 \mathrm{~nm}$ ) to avoid possible influence of the electrodes of the PEA cell.

\subsubsection{OUTGASSING ISSUES}

Cross-linking by-products are known to promote space charge formation under DC field. Predominantly heterocharge build-up, i.e. charge of polarity opposite to that of the adjacent electrode was reported [25, 26, 27]. This phenomenon is generally attributed to charge mobility enhancement due to the presence of by-products (mainly cumyl alcohol, acetophenone and alpha-methyl styrene when using dicumyl peroxide as a cross-linking agent) and the blocking nature of electrodes. Heterocharges enhance electric stress in the vicinity of the electrodes leading to a premature failure of the specimen according to the Inverse Power Law. The amount of heterocharges can be reduced by degassing the sample [28]. Actually, fully degassing a real cable may require long time and considerable energy, becoming economically unsustainable. For this reason, cables are partially degassed for the purpose of eliminating low boiling point species such as methane and ethane.

To be as close as possible to the real condition in cables, by-products concentration in plaque samples should be adjusted to the one contained in real cable. However, in general, plaque samples exhibit a very high rate of degassing due to their shape and thickness making it difficult to control the amount of by-products. For that reason, all samples were degassed, at $50{ }^{\circ} \mathrm{C}$ for 2 days to constitute a baseline for comparison of material formulation.

\subsubsection{TEST PROTOCOL}

For plaque specimens, the typical test procedure is depicted in Figure 3, consisting in polarization/depolarization at -10 , $-20,-30 \mathrm{kV} / \mathrm{mm}$, each step lasting $3 \mathrm{~h}$, up to $-40 \mathrm{kV} / \mathrm{mm}$ step followed by polarity inversion to $+40 \mathrm{kV} / \mathrm{mm}$ lasting for $3 \mathrm{~h}$, and finally depolarization measurement for $3 \mathrm{~h}$. Applied field ramps-up and ramps-down were $1 \mathrm{kV} / \mathrm{mm} / \mathrm{s}$. Cycles of $3 \mathrm{~h} / 3 \mathrm{~h}$ polarization/depolarization were chosen as a compromise between a quasi-steady state behavior and reasonable measurement time.

Ideally, plaque sample should be stressed with temperature gradient as in cable. This requires setting two different temperatures at each face of the plaque. This kind of set-up has already been developed [29, 30]. Given the thickness of sample and the PEA cell configuration, such heating system is however difficult to set-up with accurate thermal control. Hence measurements were carried out in isothermal conditions in the range of 25 to $50{ }^{\circ} \mathrm{C}$ as the maximum allowable temperature is limited to $70^{\circ} \mathrm{C}$ by the electronic part of the measuring system.

Space charge profiles were acquired all along the cycle at a frequency of 1 profile/s. Spatio-temporal evolution of space charge can be pictured by means of a cartography using a color code for representing the net charge density. This

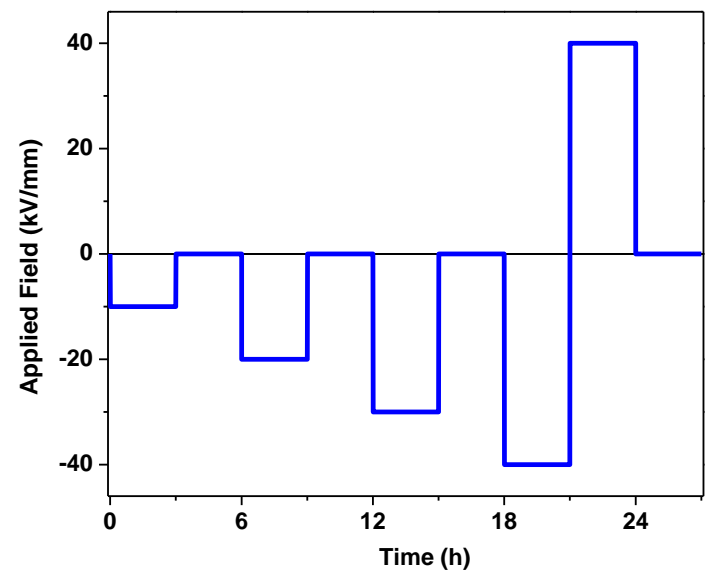

Figure 3. Stress cycle applied for space charge measurements on flat specimens.

representation enables to identify the global behavior of the material regarding space charge accumulation under different levels of field. From the observation of the cartography, one can also make a first idea about charge depletion rate during Volt-off. Furthermore, such representation is suitable to identify particular phenomena such as charge injection or heterocharges build-up. Hence, cartography of space charge can be used as a starting point for comparison between different formulations.

An example of charge pattern for gold-metalized commercial HVAC-XLPE is given in Figure 4. The measurement is done at $40{ }^{\circ} \mathrm{C}$ using the protocol of Figure 3. The time is given on $\mathrm{X}$-axis (each step lasts $3 \mathrm{~h}$ ); the thickness is along the vertical axis (anode is to the top, cathode to the bottom before polarity reversal) and the color scale represents charge density, negative and positive polarity being represented by cool (blue) and warm (yellow) colors, respectively.

For $-10 \mathrm{kV} / \mathrm{mm}$, charges are injected at both anode and cathode forming homocharges adjacent to the electrodes. A large fraction of these charges still remains after $3 \mathrm{~h}$ in Voltoff, suggesting the presence of deep traps within the bulk of the material.

For higher stress level (from -20 to $-40 \mathrm{kV} / \mathrm{mm}$ ), the bulk of the insulation is mainly dominated by negative charges that appear injected from the cathode and transported into the bulk. Negative charges enhance the field at the anode triggering an injection of positive charges as it can be seen at the beginning of the Volt-on step at $-40 \mathrm{kV} / \mathrm{mm}$. This phenomenon is even more spectacular after polarity reversal where positive charges are injected from the anode.

One has to realize here that the PEA technique as well as the other methods for space charge measurements is only sensitive to the net space charge density. A domain appearing as negatively (respectively positively) charged is a domain where the negative (positive) carriers dominate over the positive ones. One therefore has to think in terms of majority vs. minority carriers.

\subsection{CRITERIA DEFINITION}

\subsubsection{FIELD ENHANCEMENT FACTOR}




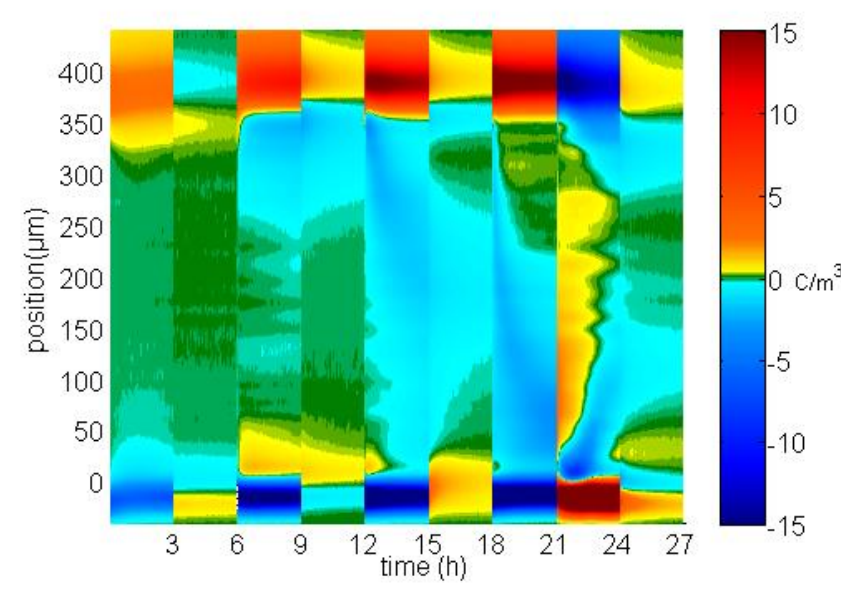

Figure 4. Space charge pattern for a gold-metalized HVAC-XLPE sample obtained using the protocol of Figure 3. The color bar represents charge density in $\mathrm{C} / \mathrm{m}^{3}$.

The Field Enhancement Factor (FEF) is defined as the ratio between the internal field and the Laplacian field. The FEF is rigorously equal to 1 along the sample thickness if no space charge is present. If charges accumulate in the dielectric, the FEF takes necessarily a value higher than the unity somewhere within the dielectric (and, conversely, a value lower than the unity somewhere else). Hence, it seems relevant to consider the evolution in time of the position where the FEF is at maximum. Also its position during a polarization step could bring interesting information. As an example, a maximum FEF in the vicinity of an electrode could be attributed to a possible presence of charges of opposite polarity to that electrode. Similarly, a maximum FEF located in the bulk is mostly due to homocharges.

Figure 5 portrays the evolution vs. time of the $F E F_{\max }$ for different electrical stresses in the case of the HVAC-XLPE sample (left column). The evolution of its position is represented on the right column. The evolution of the position of the FEF is interesting to follow, as it can be considered that interfaces constitute weak points of the system: if heterocharges are present, the FEF will be positioned close to the interfaces and this can be considered as a negative feature. For $-10 \mathrm{kV} / \mathrm{mm}$, the highest value of the field is located in the bulk (closer to the anode) as a consequence of homocharges. For higher stress $(-20$ and $-30 \mathrm{kV} / \mathrm{mm})$, a $F E F_{\max }$ of about 1.2 is reached after $3 \mathrm{~h}$ of polarization and is located next to the anode due to negative charges in the bulk. The injection of positive charges occurring at $-40 \mathrm{kV} / \mathrm{mm}$ leads to a displacement of the maximum stress from the anode to the bulk of the insulation.

\subsubsection{DYNAMIC OF SPACE CHARGE RELAXATION}

The total amount of trapped charges cannot be fully quantified by the FEF value. Consider, for example, successive layers of negative and positive charges. In this case the FEF can take a small value throughout the bulk of insulation whereas the amount of charge could be relatively high and may accelerate the material aging through the storage of electromechanical energy [17]. A more relevant way to quantify the amount of trapped charges is to compute the
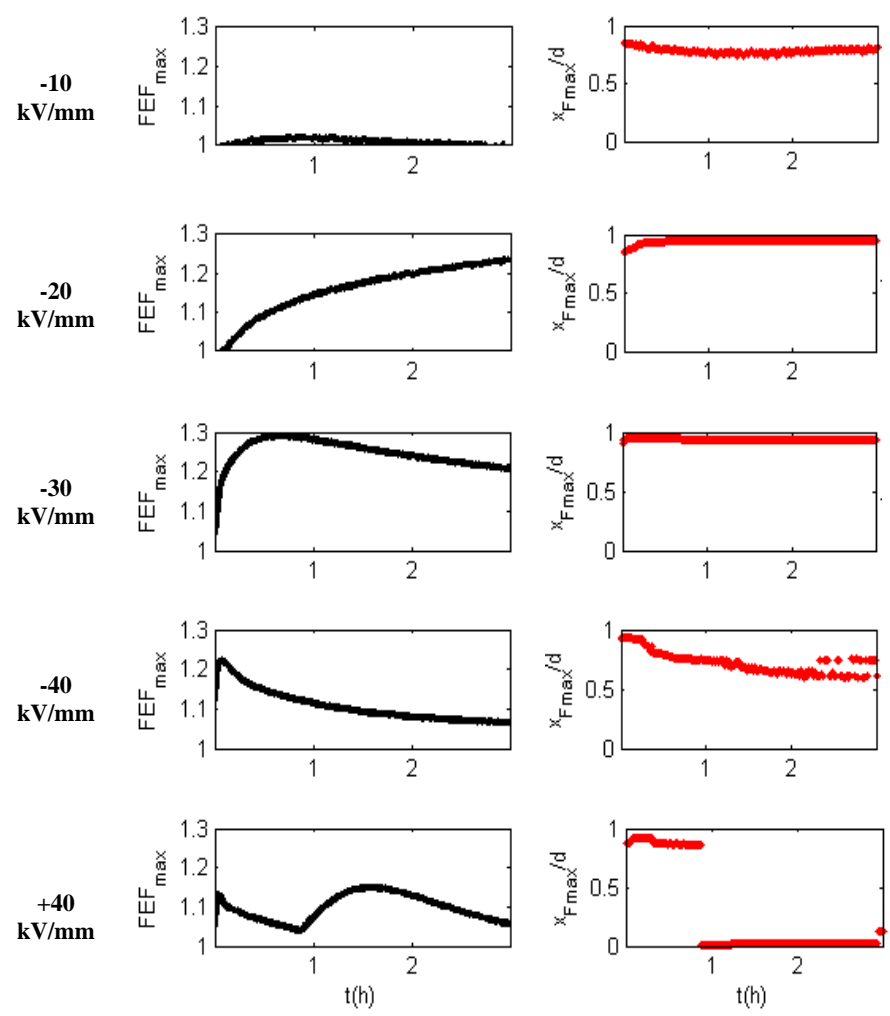

Figure 5. Left column: Evolution of the $\mathrm{FEF}_{\max }$ vs. time. Right column: evolution of the $\mathrm{FEF}_{\max }$ position vs. time under various fields for the gold-metalized HVAC-XLPE sample. Before polarity inversion, $x=0$ is the cathode, $\mathrm{x}=\mathrm{d}$ the anode.

space averaged charge density $\rho(x)$ along the sample depth:

$$
Q_{M}(t)=\frac{1}{d} \int_{0}^{d}|\rho(x, t)| d x
$$

where $d$ is the inter-electrodes distance. The value estimated immediately after grounding (in volt-off) could be considered as the amount of accumulated charges during the volt-on procedure.

Figure 6 shows the different curves of $Q_{M}(t)$ obtained during depolarization in the case of the HVAC-XLPE sample. One can notice that before polarity reversal, the amount of charges (at the beginning of depolarization) increases with the applied field. However, the value of $Q_{M}(\mathrm{t}=0,+40 \mathrm{kV} / \mathrm{mm})$ after polarity reversal falls below the one obtained after $-30 \mathrm{kV} / \mathrm{mm}$. This is due to the complex reorganization of space charges controlled by the voltage inversion, e.g. recombination between the bulk negative majority carriers and the injected positive charges following the polarity reversal (see Figure 4).

The temporal evolution of $Q_{M}(t)$ is directly related to charge detrapping. Using a proper detrapping model [31], relevant parameters related to the traps (density, apparent depth in energy) can be extracted from such curves.

For analyzing the charge decay, we consider the ensemble of charges irrespective of their nature. Charge detrapping is supposed to occur through thermal activation from traps to the conduction band and valence band, respectively for electrons 


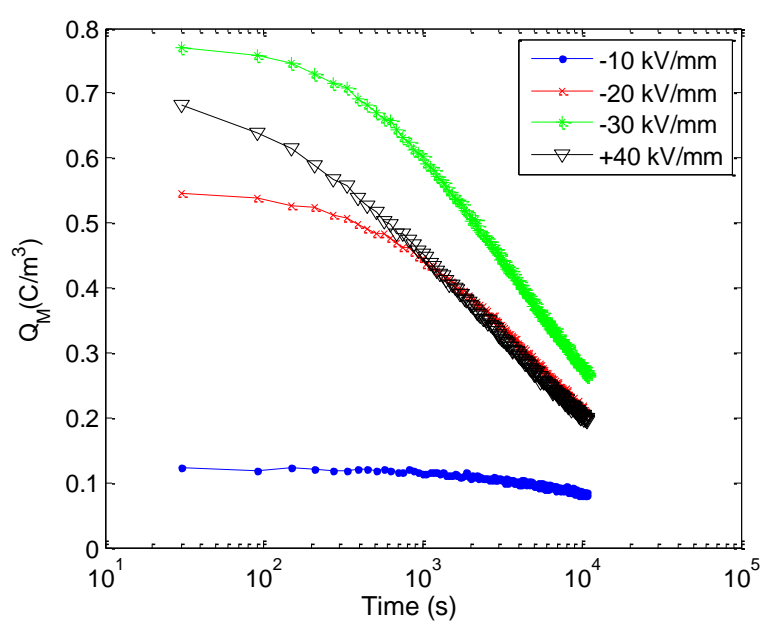

Figure 6. Time evolution of the space-averaged charge density obtained during $3 \mathrm{~h}$ in volts-off after $3 \mathrm{~h}$ polarization steps under fields indicated in the caption.

and holes - as depicted in Figure 7. Neglecting retrapping phenomena and hypothesizing a constant trap density $N_{0}$ per unit energy within a range of trap depths $\left[\Delta_{\min }-\Delta_{\max }\right]$ close to the Fermi level, it is possible as initially proposed by Dissado et al $[31,32]$ to relate the residual charge in depolarization to the minimum and maximum trap depths and to the trap density:

$$
Q_{M}(t)=N_{0} \cdot e \cdot k_{B} \cdot T\left[E_{1}\left(\omega_{\min } \cdot t\right)-E_{1}\left(\omega_{\max } \cdot t\right)\right]
$$

where $e$ is the elementary charge. Quantities $\omega_{\min }$ and $\omega_{\max }$ are linked to the emission frequency from traps $v(T)$ and to trap depths:

$$
\begin{aligned}
& \omega_{\text {min }}(T)=v(T) \cdot \exp \left(\frac{-\Delta_{\min }}{k_{B} \cdot T}\right) \\
& \omega_{\max }(T)=v(T) \cdot \exp \left(\frac{-\Delta_{\max }}{k_{B} \cdot T}\right)
\end{aligned}
$$

$E_{1}$ is the integral exponential function defined as:

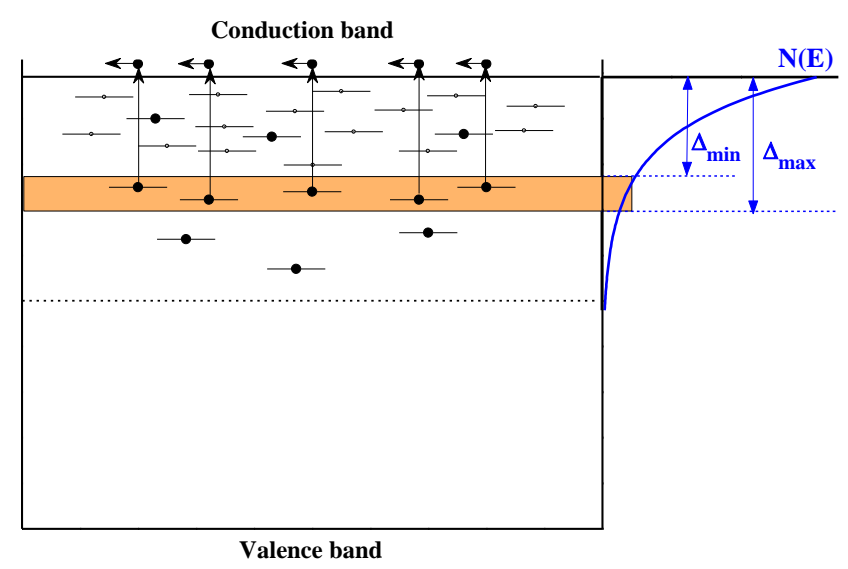

Figure 7. Model of charge detrapping by thermal activation without retrapping. Electrons only in this example.

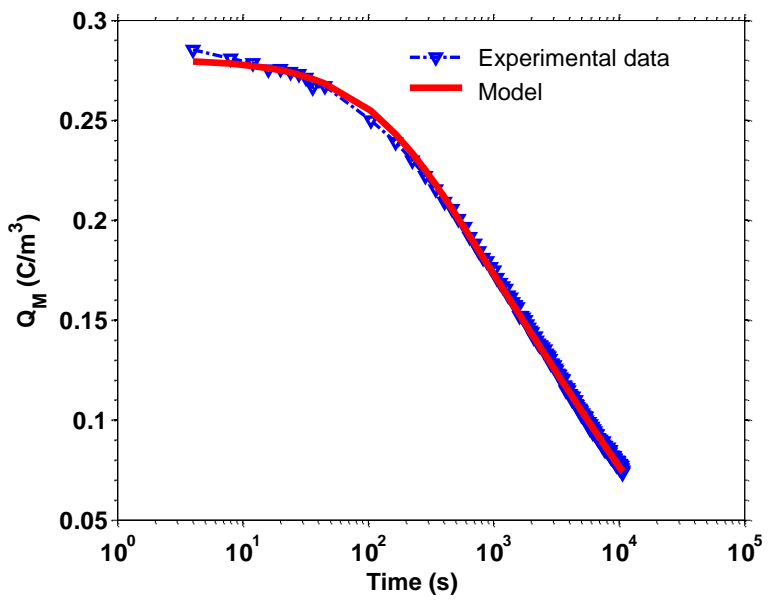

Figure 8. Example of fit of $\mathrm{Q}_{\mathrm{M}}(\mathrm{t})$ to equation 4 for a XLPE sample prepolarized under $40 \mathrm{kV} / \mathrm{mm}$ at $40^{\circ} \mathrm{C}$ for $3 \mathrm{~h}$. Fit parameters are: $\mathrm{N}_{0}=10^{19}$ $\mathrm{m}^{-3} \cdot \mathrm{eV}^{-1}, \Delta_{\min }=0.93 \mathrm{eV}$ and $\Delta_{\max }=1.1 \mathrm{eV}$. The slope of the curve provides the charge decrease rate per decade of time.

$$
E_{1}(x)=\int_{x}^{+\infty} \frac{\exp (-u)}{u} d u
$$

Fitting the experimental curves of $Q_{M}(t)$ through equation 4 provides quantities $N_{0}, \Delta_{\min }$ and $\Delta_{\max }$. An example of fit of decay curve so obtained is plotted in Figure 8. In general, acceptable fits are obtained through this procedure, whatever the material, charging conditions and temperature. It can be expected that the charge decay rate depends on the charge density since the field induced by space charge aids the transport. However, with the hypotheses taken herein, the rate limiting step in sample discharge is considered as being detrapping of charges and not their drift to the electrodes. Combining equations 4 through 6 gives:

$$
Q_{M}(t=0)=Q_{M 0}=e \cdot N_{0} \cdot\left[\Delta_{\max }-\Delta_{\min }\right]
$$

The charge resorption rate, expressed in \% per decade in time depends on the trap depth range:

$$
s=\frac{1}{Q_{M 0}} \cdot \frac{d Q_{M}(t)}{d \log (t)}=\frac{-k_{B} T}{\Delta_{\text {max }}-\Delta_{\min }} \ln (10)
$$

Among the above quantities, the effect of the charge relaxation rate is worth discussing. A slow relaxation of charges implies that at polarity reversal the residual field will add to the applied field. If homocharges were present before field inversion, it means that field reinforcement on the interfaces, which are considered as weak points, will be present at polarity reversion. Improvement of XLPE withstanding to polarity inversion stresses was observed with incorporation of tree-retardant additives [33]. The effect was explained by the dissipation of injected charges away from the injecting electrode and hence to the mitigation of field intensification effect at polarity inversion. Lifetime measurements carried out by Cavallini et al. on different materials [20] point along that direction, with an inverse correlation of charge release rate with life.

On another respect, it can be argued that fast space charge relaxation can trigger the release of energetic carriers and 
produce some ageing effects to the insulation. Resorting to long term degradation and life models, generally static processes involving electrostatic or electromechanical energy are considered $[34,35]$; however, under fast varying voltages, carriers accelerated in defective/lower density region of the material may trigger defects growth and contribute to life reduction $[36,37]$. Therefore, the interpretation of the criterion has to be appreciated depending on whether polarity inversion has to be applied and on expected switching rates of the system.

Combining equations (2), (7) and (8) one gets the following relation between quantities extracted from space charge measurements and lifetime with polarity inversion, for a given applied stress:

$$
L_{I} \propto \frac{1}{F E F_{\max }^{N}\left(1+a_{O} \cdot N_{0}\left(\frac{\Delta_{\max }-\Delta_{\min }}{k_{B} T}\right)^{1+a_{1}} k_{B} \cdot T \cdot f^{a_{2}}\right)}
$$

where $N_{0}, a_{0}, a_{1}$ and $a_{2}$ are positive quantities. This expression highlights the detrimental effect of field distortion, charge quantity and apparent trap depth on expected lifetime.

In practice, considering data obtained on various materials, variations in the decay rate are mainly due to variations in the maximum trap depth. To sum up, the spatio-temporal charge distribution obtained on flat specimen under charging and discharging steps with various voltages are analyzed considering as main output parameters:

- the FEF obtained in volts-on for typical polarization time of $3 \mathrm{~h}$ : a single parameter extracted can be the maximum of FEF obtained during the step;

- the initial quantity of charges when switching off the voltage;

- the maximum in trap depth, that represents the capability of the material to permanently store the charges.

Eventually the position in the insulation where the FEF is at maximum and the minimum trap depth are worth considering. In the following we show examples of the application of such criteria for a comparison of the performance of different materials that are candidate for insulation in HVDC.

\section{APPLICATION TO MATERIALS SCREENING}

The screening procedure is illustrated below through a comparison of different materials involved in DC insulation development. In a first step, we compare space charge features on the LDPE resin serving as basis for DC-XLPE to the same material soaked into acetophenone, reaching a concentration of $1 \mathrm{wt} . \%$, which is the order of magnitude of the concentration found in peroxide-crosslinked materials. In a second step, we compare the features obtained on AC-XLPE (XLPE-1) previously described to those obtained on peroxidecrosslinked XLPE (XLPE-2) providing similar features to a commercial grade HVDC product and that obtained with a crosslinking process based on the use of co-agents of crosslinking with allylic functions (XLPE-3) [38]. The process requires a much lesser amount of peroxide and is virtually without by-products. No thermal treatment was achieved in the latter case before measurements.

\subsection{LOW DENSITY POLYETHYLENES}

Figure 9 shows the space charge patterns obtained on LDPE and acetophenone-soaked LDPE, with initially $1 \%$ wt. concentration. Both samples were gold-coated and measurements were carried out at $40^{\circ} \mathrm{C}$. A relatively small amount of charges is detected on LDPE with the current stressing conditions. These are essentially negative charges detected, still visible after polarity reversal. The residual charge density at the beginning of the Volt-off step is given in Table 1. It increases only slightly with the applied stress.

Comparatively, the acetophenone soaked sample reveals a much larger amount of negative charges occupying the whole volume and tending to accumulate at the anode. At polarity reversal, a front of positive charges is detected in the first minutes, and then negative charges dominate again. The buildup of this negative space charge may correspond to trapping of electronic carriers by the molecule or to field-induced ionization effects. A $F E F_{\text {max }}$ as high as 1.5 has been found for this material whichever the stress, cf. Table 1.

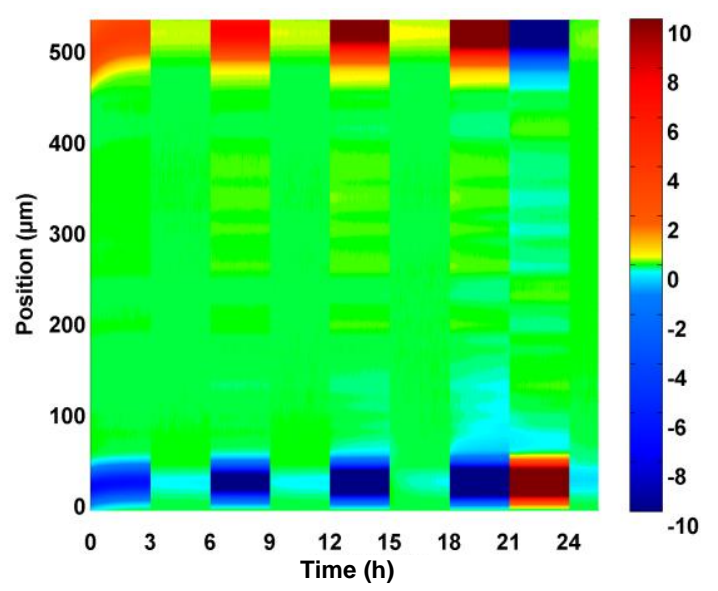

(a) LDPE

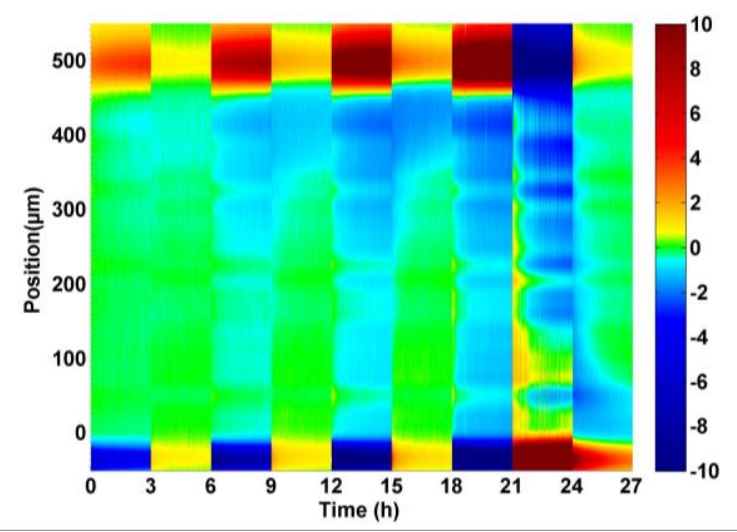

(b) LDPE + 1\% wt. acetophenone

Figure 9. Space charge pattern obtained on LDPE (a) and acetophenonesoaked LDPE (b) using the stress cycle shown in Fig. 3. The color bar provides charge density in $\mathrm{C} / \mathrm{m}^{3}$. 


\subsection{CROSSLINKED POLYETHYLENES}

Space charge patterns for the crosslinked polyethylenes are shown in Figures 4 and 10. Compared to the AC-XLPE (Figure 4), the patterns in Figure 10 clearly reveal fewer charges and are somewhat less complex. In XLPE-1, the charge switches from homocharge to heterocharge, depending on stress conditions, as if there were competition between injection and dissociation. For XLPE-2 (Figure 10a), carriers appear mainly due to injection at the electrodes, with a nearly symmetrical density and position at low field and with positive charges dominating over negative ones at higher field. For XLPE-3 (Figure 10b), the charge tends to be negative before polarity reversal (as for LDPE-1). Positive charges appear next to the bottom electrode after inversion, presumably due to the field amplification resulting from to the previously stored negative charges. The residual charge densities after switching off the voltage are particularly low for XLPE-3, being of the order of $0.1 \mathrm{C} / \mathrm{m}^{3}$ for the first 3 levels of stress and of $0.3 \mathrm{C} / \mathrm{m}^{3}$ for the last one. Also, the FEF is low.

\section{DISCUSSION}

\subsection{OUTPUTS FOR MATERIALS ASSESSMENT}

Considering the parameter values of $F E F_{\max }$ and $Q_{M 0}$ extracted for LDPE samples, it appears obvious that acetophenone exhibits a considerable role on the space charge

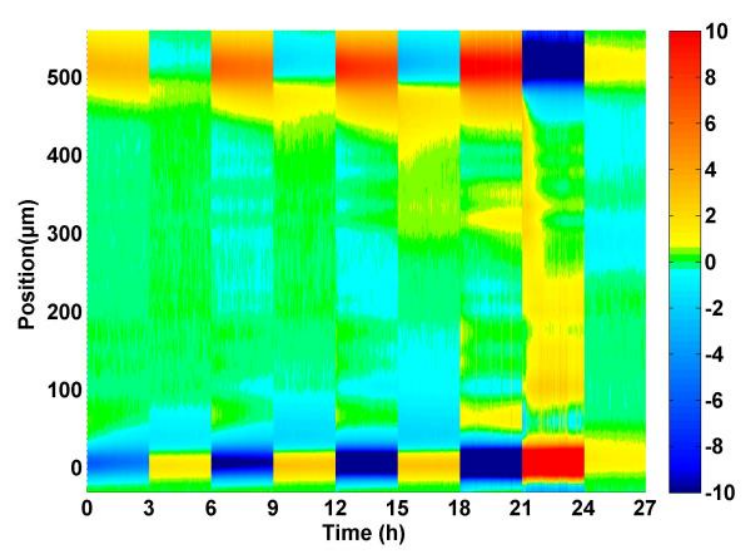

(a) XLPE-2

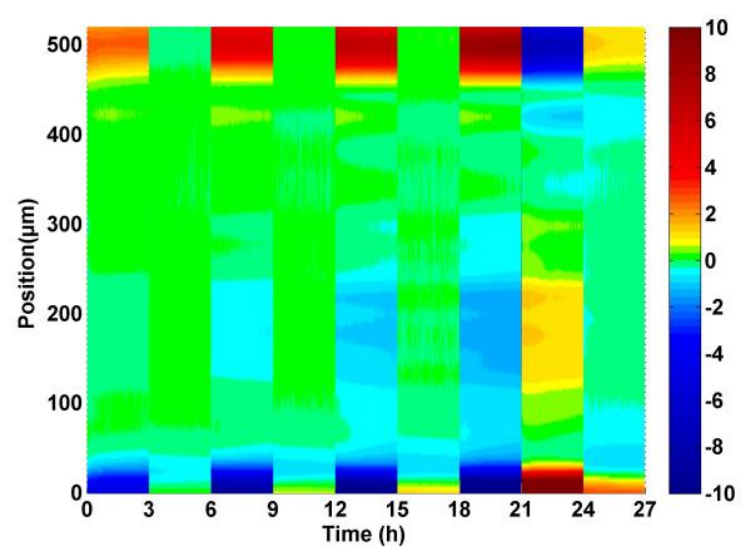

(b) XLPE-3

Figure 10. Space charge patterns obtained on peroxide-crosslinked material (a) and crosslinking process without by-products (b) with the same stress conditions and representation of data as in Figure 9.
Table 1. Sum-up of space charge data for some of the tested insulations.

\begin{tabular}{|c|c|c|c|c|c|c|}
\hline \multicolumn{2}{|c|}{$\mathbf{F}_{\text {app }}(\mathrm{kV} / \mathrm{mm})$} & -10 & -20 & -30 & -40 & 40 \\
\hline \multirow{2}{*}{ LDPE-1 } & $\mathrm{FEF}_{\text {max }}$ & 1.06 & 1.05 & 1.07 & 1.09 & 1.09 \\
\hline & $\mathrm{Q}_{\mathrm{M} 0}\left(\mathrm{C} / \mathrm{m}^{3}\right)$ & 0.08 & 0.08 & 0.12 & -- & 0.13 \\
\hline \multirow{4}{*}{$\begin{array}{c}\text { LDPE-2 } \\
(1 \% \\
\text { acetophenone })\end{array}$} & $\mathrm{FEF}_{\text {max }}$ & 1.50 & 1.53 & 1.53 & 1.53 & 1.47 \\
\hline & $\mathrm{Q}_{\mathrm{M} 0}\left(\mathrm{C} / \mathrm{m}^{3}\right)$ & 0.25 & 0.63 & 0.97 & -- & 1.45 \\
\hline & $\Delta_{\min }(\mathrm{eV})$ & 1.04 & 1.00 & 0.92 & -- & 0.96 \\
\hline & $\Delta_{\max }(\mathrm{eV})$ & 1.14 & 1.14 & 1.13 & -- & 1.07 \\
\hline \multirow{4}{*}{$\begin{array}{l}\text { XLPE-1 } \\
\text { (AC-XLPE, } \\
\text { peroxide, } \\
\text { outgassed) }\end{array}$} & $\mathrm{FEF}_{\text {max }}$ & 1.02 & 1.25 & 1.30 & 1.23 & 1.15 \\
\hline & $\mathrm{Q}_{\mathrm{M} 0}\left(\mathrm{C} / \mathrm{m}^{3}\right)$ & 0.13 & 0.52 & 0.78 & -- & 0.67 \\
\hline & $\Delta_{\min }(\mathrm{eV})$ & 1.02 & 0.98 & 0.97 & -- & 0.95 \\
\hline & $\Delta_{\max }(\mathrm{eV})$ & 1.13 & 1.10 & 1.11 & -- & 1.11 \\
\hline \multirow{4}{*}{$\begin{array}{l}\text { XLPE-2 } \\
\text { (peroxide, } \\
\text { outgassed) }\end{array}$} & $\mathrm{FEF}_{\text {max }}$ & 1.10 & 1.13 & 1.10 & 1.05 & 1.15 \\
\hline & $\mathrm{Q}_{\mathrm{M} 0}\left(\mathrm{C} / \mathrm{m}^{3}\right)$ & 0.26 & 0.45 & 0.75 & -- & 0.35 \\
\hline & $\Delta_{\min }(\mathrm{eV})$ & 1.05 & 1.03 & 1.02 & -- & 1.05 \\
\hline & $\Delta_{\max }(\mathrm{eV})$ & 1.14 & 1.19 & 1.17 & -- & 1.13 \\
\hline \multirow{4}{*}{$\begin{array}{c}\text { XLPE-3 } \\
\text { (without } \\
\text { by-products) }\end{array}$} & $\mathrm{FEF}_{\text {max }}$ & 1.07 & 1.05 & 1.05 & 1.06 & 1.02 \\
\hline & $\mathrm{Q}_{\mathrm{M} 0}\left(\mathrm{C} / \mathrm{m}^{3}\right)$ & 0.10 & 0.09 & 0.09 & -- & 0.33 \\
\hline & $\Delta_{\min }(\mathrm{eV})$ & 1.01 & 1.02 & 1.04 & -- & 1.03 \\
\hline & $\Delta_{\max }(\mathrm{eV})$ & 1.16 & 1.21 & 1.22 & -- & 1.17 \\
\hline
\end{tabular}

response, especially with promoting the formation of negative heterocharges whatever the applied field, and with as consequence an increase in the local field by about $50 \%$ in respect to the applied field. The features appear consistent with earlier reports [39].

The AC-grade XLPE has really poor performances comparatively to the other two materials and the features support the efforts put along the years to develop crosslinked materials with improved properties in terms of space charge features [12, 40, 41]. Comparing features for XLPE-2 and 3, both the $F E F_{\max }$ and the residual charge $Q_{M 0}$ appear lower for the latter before polarity inversion at $40 \mathrm{kV} / \mathrm{mm}$. Quantities approach here those obtained for LDPE-1. After polarity inversion, XLPE-3 performs as well as XLPE-2. Only the charge dissipation rate, reflected by the value of $\Delta_{\max }$, is larger for XLPE-3, for all stress levels. The very fact that charge density is less might be one of the reasons for the slower charge release and hence larger apparent trap depth. Indeed, the residual field that controls charge transport is not taken into account in the detrapping kinetic model. Overall, XLPE3 , which was crosslinked without by-products, exhibits better performances. This is all the more remarkable that it was obtained without thermal conditioning of the material, which could also evacuate volatile residues like water.

The effects of by-products, among which acetophenone incorporated into LDPE or present as cross-linking residue within XLPE, are investigated for long for their detrimental properties to charge accumulation. Nevertheless, there is no 
general agreement on the details of the mechanisms at play. When acetophenone is incorporated into LDPE, space charge accumulation is observed, sometimes as heterocharge features, and electrical conductivity is increased. Three processes can be envisaged, being injection-assisted process for electronic carriers [42], transport-assisted process for these charges [43], and promotion of ionic transport either by direct ionization of acetophenone under the field or indirectly through ion solvation effects. As an example, Hozumi et al [44] have shown that saturation of acetophenone into LDPE favors the injection of negative charges. Charge packets can be formed by solvation of impurities into acetophenone [45]. Finally according to Kobayashi et al [46], the conduction into acetophenone-containing LDPE is of ionic type.

In results presented above, acetophenone clearly promotes the formation of a negative space charge into LDPE. The same effects are observed at all fields in XLPE-1 and at moderate fields $(10-20 \mathrm{kV} / \mathrm{mm})$ in XLPE-2. For high fields $(40 \mathrm{kV} / \mathrm{mm})$, positive and negative charges coexist. The behavior of by-products into XLPE is more complex, owing to the presence of several species and on possible interactions with antioxidants. The new feature is that through a crosslinking process that does not lead to by-products, materials with much less pronounced space charge phenomena can be produced, which points on the very effects of byproducts when dealing with peroxide crosslinked materials.

At the present time such alternative crosslinking scheme has not been transferred to the industrial scale. Therefore, peroxide crosslinking is still used. Obviously, though the trend is to reduce the amount of peroxide, crosslinked cables have to be degassed, at least partially, in order to reduce heterocharges. However, the degassing process consumes considerable amounts of energy. For instance, 43 days at $60{ }^{\circ} \mathrm{C}$ are required to remove $50 \%$ of the initial concentration of acetophenone contained in the middle of the insulation for a 18 mm-thick XLPE insulated HV power cable [47]. Thus developing processes leading to less charge accumulation are highly desirable.

\subsection{REPRESENTATIVENESS FOR DC CABLES}

The extension of the above approaches to model cables and to full size cables would be of course desirable for guaranteeing the validity of the method, this, all the more that devices for measurement on full size cables become available [48, 49]. However, at the stage of materials screening and particularly for formulation purpose this would be very heavy to implement as optimization concerns not only the insulation (nature of base resin, crosslinking agent and antioxidant) but also the semicon (matrix, carbon black and processing agents). As the possibilities for changing composition are far larger for the later, the sampling matrix for the full study would require a large number of cables to be produced. At the stage of materials selection, flat specimens certainly constitute a lighter approach and also may provide the possibility of carrying out a deeper investigation.

Some comments are worth giving on the transposition of results from flat specimen to cable scale. The association of semicon and insulation can be checked applying the PEA technique on sandwich structures processed as described in section 2.2. An example of space charge pattern obtained in commercial materials crosslinked altogether is shown in Figure 11. The pattern reveals the formation of heterocharges (in relatively low amount) and a substantial positive charge injection upon polarity reversal. The geometry itself (cable vs. flat geometry) does not constitute an obstacle for screening since if materials are well characterized in plaque form, with the relevant field range, then it should be possible to anticipate their behavior in case of non-uniform field. The reciprocal is not true however. Indeed, features for cables response, including space charge response, are brought about by nonlinear conduction and thermal gradients, as addressed in the introduction. In many instances, it becomes extremely difficult to discriminate for example charge build up due to ion migration from that relevant to conductivity gradient. So for pure material approaches, homogeneous field is preferable.

Sample thickness (about $500 \mu \mathrm{m}$ herein vs. several $\mathrm{cm}$ within full size cables) and conditioning probably constitute more debatable aspects. Concerning thickness, it is generally observed that charge release after DC stressing decreases when the material thickness increases. For example, Fu et al [27] showed that, in MV cables with $4 \mathrm{~mm}$ thick insulation, the heterocharge build up under a given polarity subsists after stressing for more than $30 \mathrm{~min}$ under the reverse polarity. Also, we have observed that pre-stressed MV cables may retain their charge for months in Volt-off and ambient conditions. Such features are usually not observed in thin samples. This can be understood since charge redistribution implies transit over longer distances.

Outgassing is another key point in the space charge behavior. Clearly it is extremely difficult to test plaque samples or even miniature cable samples pretending to be in conditions representative of $\mathrm{HV}$ cables regarding by-products concentrations $[13,28]$. Expelling is a relatively fast process in plaque samples, and as DC testing necessarily requires long testing times, combined with thermal stress, initially freshly crosslinked samples necessarily evolve during the testing time. For these reasons, thermal annealing is most always achieved prior to testing. Even though thermal treatment was achieved, present results have confirmed, in line with earlier works, that crosslinking by-products are detrimental to materials performance regarding space charge criteria. Therefore, there

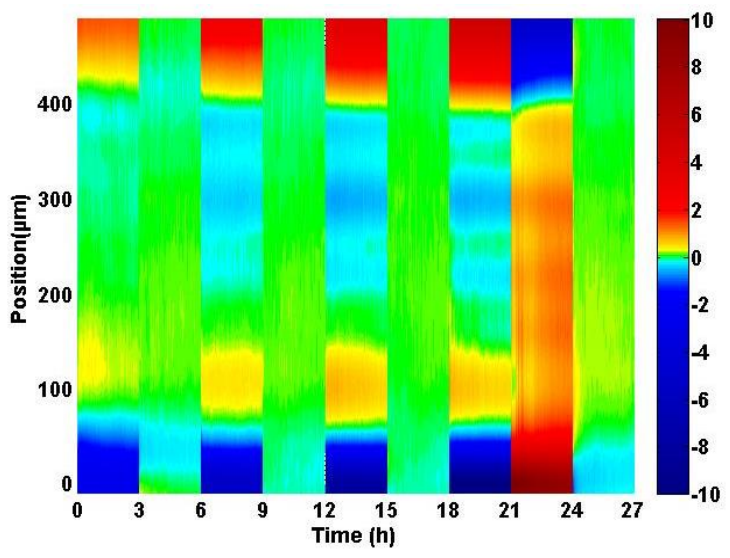

Figure 11. Space charge pattern obtained applying the stress cycle of Figure 3 on a sandwich structure SC/XLPE/SC crosslinked altogether. 
is no more real challenge regarding the effect of crosslinking residues.

\section{CONCLUSION}

We have presented a methodology for assessing insulation as well as semicon materials for use in HVDC cables application from the standpoint of space charge characteristics. Materials figures of merit are defined in line with life models of insulations under DC stress, which encompass materials endurance under polarity reversal. Quantities of interest are maximum field distortion, residual charge density after DC stressing and parameters related to the kinetics of charge release. The use of such quantities, though resulting in a coarser picture of material response than space charge patterns may provide, has the advantage of permitting a direct material-to-material comparison, including comparison of materials association. Though the examples are given for flat specimen, in principle the procedure can be extended to cable geometry samples. Using this methodology, we confirm earlier reports on the detrimental effects of crosslinking byproducts regarding space charge features considering crosslinking of LDPE initiated by peroxide radicals.

\section{ACKNOWLEDGMENTS}

We are greatly indebted to Dr M. Mammeri, I. Denizet and J.C. Gard from Silec Cable for their support of this study.

\section{REFERENCES}

[1] G. Mazzanti, M. Marzinotto, "Extruded Cables for High-voltage DirectCurrent Rransmission", Wiley-IEEE Press, New Jersey, USA, 2013.

[2] G. Chen, M. Hao, Z.Q. Xu, A. Vaughan, J.Z. Cao and H.T. Wang, "Review of high voltage direct current cables", J. Power Energy Systems, Vol. 1, pp. 9-21, 2015.

[3] T.L. Hanley, R.P. Burford, R.J. Fleming and K.W. Barber, "A general review of polymeric insulation for use in HVDC cables", IEEE Electr. Insul. Mag., Vol. 19, No. 1, pp. 13-24, 2003.

[4] H. Ghorbani, M. Jeroense, C.O. Olsson and M. Saltzer, "HVDC cable systems-highlighting extruded technology", IEEE Trans. Power Delivery, Vol. 29, pp. 414-421, 2014.

[5] M. Jeroense, M. Saltzer, and H. Ghorbani, "Technical challenges linked to HVDC cable development", Revue Electricité Electronique, No. 4, pp. III-X, 2014.

[6] D. Fabiani, G.C. Montanari, C. Laurent, G. Teyssedre, P.H.F. Morshuis, R. Bodega and L.A. Dissado, "HVDC cable design and space charge accumulation. Part 3: Effect of temperature gradient", IEEE Electr. Insul. Mag., Vol. 24, No 2, pp. 5-14, 2008.

[7] S. Boggs, H. Dwight, J. Hjerrild, J.T. Holbol, and M. Henriksen, "Effect of insulation properties on the field grading of solid dielectric DC cable", IEEE Trans. Power Deliv., Vol. 16, pp. 456-462, 2001.

[8] T.T.N. Vu, G. Teyssedre, B. Vissouvanadin, S. Le Roy and C. Laurent, "Correlating conductivity and space charge measurements in multidielectrics under various electrical and thermal stresses", IEEE Trans. Dielectr. Electr. Insul., Vol. 22, pp. 117-127, 2015.

[9] P.H.F. Morshuis, R. Bodega, D. Fabiani, G.C. Montanari, L.A. Dissado and J.J. Smit, "Dielectric interfaces in DC constructions: space charge and polarization phenomena", IEEE Int'l. Conf. Solid Dielectr. (ICSD), pp. 450-453, 2007.
[10] T. Vu-Cong, A. Beroual, A. Girodet and P. Vinson, "Time constant evaluation of transient AC - DC field distribution", 19th Int'l. Sympos. High Voltage Engg (ISH), pp. 1-7, 2015.

[11] C.O. Olsson, "Modelling of thermal behaviour of polymer insulation at high electric dc field", 5th European Thermal-Sciences Conf., pp. 1-8, 2008.

[12] T. Hjertberg, V. Englund, P.O. Hagstrand, W. Loyens, U. Nilsson and A. Smedberg, "Materials for HVDC cables", Revue Electricité Electronique, No. 4, pp. XI-XV, 2014.

[13] U.H. Nilsson, J. Andersson, V. Englund, V. Eriksson, P.O. Hagstrand and A. Smedberg, "The role and measurement of dc conductivity for HVDC cable insulation materials", IEEE Conf. Electr. Insul. Dielectr. Phenom. (CEIDP), pp. 31-34, 2015.

[14] B. Aladenize, R. Coelho, F. Guillaumond and P. Mirebeau, "On the intrinsic space charge in a DC power cable", J. Electrostat., Vol. 39, pp. 235-251, 1997.

[15] I.W. McAllister, G.C. Crichton and A. Pedersen, "Charge accumulation in DC cables: A macroscopic approach," IEEE Int'l. Sympos. Electr. Insul. (ISEI), pp. 212-216, 1994

[16] B. Vissouvanadin, G. Teyssèdre, S. Le Roy, C. Laurent, I. Denizet, M. Mammeri and B. Poisson, "A methodology for the assessment of HVDC-XLPE cable insulation", 8th Int'1 Conf. Power Insulated Cables (Jicable), pp. 50-55, 2011.

[17] L.A Dissado, G. Mazzanti and G.C. Montanari, "The role of trapped space charges in the electrical aging of insulating materials", IEEE Trans. Dielectr. Electr. Insul., Vol. 4, pp. 496-505, 1997.

[18] Cigré Working Group 21.01, "Recommendations for testing DC extruded Cable systems for power transmission at rated voltage up to 250 kV", pp. 1-29, 2003

[19] G.C. Montanari and D. Fabiani, "Evaluation of dc insulation performance based on space-charge measurements and accelerated life tests", IEEE Trans. Dielectr. Electr. Insul., Vol. 7, pp. 322-328, 2000.

[20] A. Cavallini, D. Fabiani, G. Mazzanti and G.C. Montanari, "Life model based on space-charge quantities for HVDC polymeric cables subjected to voltage-polarity inversions", IEEE Trans. Dielectr. Electr. Insul., Vol. 9, pp. 514-523, 2002.

[21] T. Maeno, T. Futami, H. Kushibe, T. Takada and C.M. Cooke, "Measurement of spatial charge distribution in thick dielectric using the pulsed electro-acoustic method", IEEE Trans. Electr. Insul., Vol. 23, pp. 433-439, 1988.

[22] S. Delpino, D. Fabiani, G.C. Montanari, L. A. Dissado, C. Laurent and G. Teyssedre, "Fast charge packet dynamics in XLPE insulated cable models", IEEE Conf. Electr. Insul. Dielectr. Phenom. (CEIDP), pp. 421-424, 2007.

[23] M. Fu and G. Chen, "Space charge measurement in polymer insulated power cables using flat ground electrode PEA system", IEE. Proc. Sci. Meas. Technol., Vol. 150, pp. 89-96, 2003.

[24] B. Vissouvanadin, T.T.N. Vu, L. Berquez, S. Le Roy, G. Teyssèdre and C. Laurent, "Deconvolution techniques for space charge recovery using pulsed electroacoustic method in coaxial geometry", IEEE Trans. Dielectr. Electr. Insul., Vol. 21, pp. 821-828, 2014.

[25] W.S. Lau and G. Chen, "Simultaneous space charge and conduction current measurements in solid dielectrics under high dc electric field", Int'l. Conf. Condition Monitoring and Diagnosis (CMD), pp. 1-6, 2006.

[26] M. Fu, G. Chen, L.A. Dissado and J.C. Fothergill, "Influence of thermal treatment and residues on space charge accumulation in XLPE for DC power cable application", IEEE Trans. Dielectr. Electr. Insul., Vol.14, pp.53-64, 2007.

[27] M. Fu, L.A. Dissado, G. Chen and J.C. Fothergill, "Space charge formation and its modified electric field under applied voltage reversal and temperature gradient in XLPE cable," IEEE Trans. Dielectr. Electr. Insul., Vol. 15, pp. 851-860, 2008. 
[28] B. Vissouvanadin, S. Le Roy, G. Teyssedre, C. Laurent, I. Denizet, M. Mammeri and B. Poisson, "Impact of concentration gradient of polarizable species on the electric field distribution in polymeric insulating material for HVDC cable", IEEE Trans. Dielectr. Electr. Insul., Vol. 18, pp. 833-839, 2011.

[29] X. Chen, X. Wang, K. Wu, Z.R. Peng, Y.H. Cheng and D.M. Tu, "Space charge measurement in LDPE films under temperature gradient and DC stress", IEEE Trans. Dielectr. Electr. Insul., Vol. 17, pp. 1796-1805, 2010

[30] Z. Lv, J. Cao, X. Wang, H. Wang, K. Wu and L.A. Dissado, "Mechanism of space charge formation in cross linked polyethylene (XLPE) under temperature gradient", IEEE Trans. Dielectr. Electr. Insul., Vol. 22, pp. 3186-3196, 2015.

[31] L.A. Dissado, O. Paris, T. Ditchi, C. Alquie and J. Lewiner, "Space charge injection and extraction in high divergent fields," IEEE Conf. Electr. Insul. Dielectr. Phenom. (CEIDP), pp. 23-26, 1999.

[32] L.A. Dissado, V. Griseri, W. Peasgood, E.S. Cooper, K. Fukunaga and J. Fothergill, "The decay of space charge in a glassy epoxy resin following voltage removal", IEEE Trans. Dielectr. Electr. Insul., Vol. 13, pp. 903-916, 2006.

[33] M. Abou-Dakka, A.T. Bulinski and S.S. Bamji, "Space charge evolution in XLPE with long-term aging under DC voltage - the effect of temperature and polarity reversals," IEEE Conf. Electr. Insul. Dielectr. Phenom. (CEIDP), pp. 537-540, 2006.

[34] L.A. Dissado, G. Mazzanti and G.C Montanari, "The incorporation of space charge degradation in the life model for electrical insulating materials", IEEE Trans. Dielectr. Electr. Insul., Vol. 2, pp. 1147-1158, 1995.

[35] G. Mazzanti, G.C Montanari, and L.A. Dissado, "Electrical aging and life models: the role of space charge", IEEE Trans. Dielectr. Electr. Insul., Vol. 12, pp. 876-890, 2005.

[36] G.C. Montanari, "Bringing an insulation to failure: the role of space charge", IEEE Trans. Dielectr. Electr. Insul., Vol. 18, pp. 339-364, 2011.

[37] C. Laurent, G. Teyssèdre, S. Le Roy and F. Baudoin, "Charge dynamics and its energetic features in polymeric materials", IEEE Trans. Dielectr. Electr. Insul., Vol. 20, pp. 357-381, 2013.

[38] J.C. Gard, I. Denizet and M. Mammeri, "Development of a XLPE insulating with low peroxide by-products", Proc. 9th Int'l Conference on Insulated Power Cables (Jicable), pp. 1-5, 2015.

[39] Y. Maeno, N. Hirai, Y. Ohki, T. Tanaka, M. Okashita and T. Maeno, "Effects of crosslinking byproducts on space charge formation in crosslinked polyethylene," IEEE Trans. Dielectr. Electr. Insul., Vol. 12, pp. 90-97, 2005.

[40] D. Fabiani, G. C Montanari, C. Laurent, G. Teyssedre, P.H.F. Morshuis, R. Bodega, L.A. Dissado, A. Campus and U.H. Nilsson, "Polymeric HVDC cable design and space charge accumulation. Part 1: insulation/semicon interface", IEEE Electr. Insul. Mag., Vol. 23, No 6, pp. 11-19, 2007.

[41] A. Smedberg, T. Hjertberg and B. Gustafsson, "Effect of molecular structure and topology on network formation in peroxide crosslinked polyethylene", Polymer, Vol. 44, pp. 3395-3405, 2003.

[42] Y. Li, M. Yasuda and T. Takada, "Influence on spatial charge distribution of cross-linking agent residues in XLPE", Int'l Conf. Prop. Appl. Dielectr. Mater. (ICPADM), pp. 1210-1213, 1991.

[43] N. Hussin and G. Chen, "The Effect of acetophenone and alphamethylstyrene on the space charge properties of low density polyethylene," IEEE Conf. Electr. Insul. Dielectr. Phenom. (CEIDP), pp. 702-705, 2008.

[44] N. Hozumi, H. Matsumura, Y. Murakami and S. Mitsumoto, "Carrier mobility in acetophenone-soaked polyethylene estimated by transient space charge," Int'l. Conf. Prop. Appl. Dielectr. Mater. (ICPADM), pp. 943-946, 2000.

[45] N. Hozumi, T. Takeda, H. Suzuki and T. Okamoto, "Space charge behavior in XLPE cable insulation under $0.2-1.2 \mathrm{MV} / \mathrm{cm}$ dc fields," IEEE Trans. Dielectr. Electr. Insul., Vol. 5, pp. 82-90, 1998.

[46] K. Kobayashi, T. Ohara, Y. Ohki and T. Maeno, "Effect of acetophenone on the space charge evolution in LDPE and LLDPE," IEEE Conf. Electr. Insul. Dielectr. Phenom. (CEIDP), pp. 27-31, 1999.

[47] T. Andrews, R.N. Hampton, A. Smedberg, D. Wald, V. Waschk and W. Weissenberg, "The role of degassing in XLPE power cable manufacture", IEEE Electr. Insul. Mag., Vol. 22, No. 6, pp. 5-16, 2006.

[48] J. Castellon, P. Notingher, S. Agnel, A. Toureille, F. Brame, P. Mirebeau and J. Matallana, "Electric field and space charge measurements in thick power cable insulation", IEEE Electr. Insul. Mag., Vol. 25, No. 3, pp. 30-42, 2009.

[49] A. Tzimas, G. Lucas, K. Dyke, F. Perrot, L. Boyer, P. Mirebeau, S. Dodd, J. Castellon and P. Notingher, "Space charge evolution in XLPE HVDC cable with Thermal-Step-Method and Pulse-Electro-Acoustic", Proc. 9th Int'1 Conf. Insulated Power Cables (Jicable), Paper A8.1, pp. 1-6, 2015.

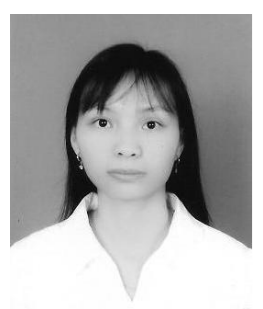

Thi Thu Nga Vu was born in September 1981 in Hanoi, Vietnam. She received the Diploma in electrical engineering in 2004 and the Master's degree in 2007 from the Hanoi University of Science and Technology, in Vietnam. She has been working since 2004 as a researcher and lecturer at the Electric Power University in Hanoi, Vietnam. She received the Ph.D. degree in electrical engineering from the University of Toulouse in July 2014 for a research work on space charge accumulation and related phenomena in polymeric insulating materials intended for HVDC cable application at the LAPLACE in Toulouse, France

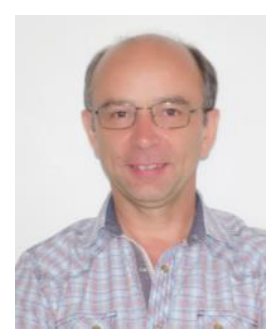

Gilbert Teyssedre was born in May 1966 in Rodez, France. He received his Engineer degree in materials physics and graduated in solid state physics in 1989 at the National Institute for Applied Science (INSA). Then he joined the Solid State Physics Lab in Toulouse and obtained the $\mathrm{Ph} . \mathrm{D}$. degree in 1993 for work on ferroelectric polymers. He entered the CNRS in 1995 and has been working since then at the Electrical Engineering Lab (now LAPLACE) in Toulouse. His research activities concern the development of luminescence techniques in insulating polymers with focus on chemical and physical structure, degradation phenomena, space charge and transport properties. He is currently Research Director at CNRS in a team working on the reliability of dielectrics in electrical equipment.

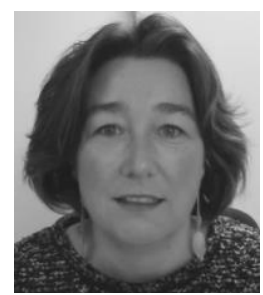

Séverine Le Roy was born on 30 August 1977 in Belfort, France. She graduated in molecular and structural physical chemistry in 2001 at the Joseph Fourier University, Grenoble, France. Then she joined the Electrical Engineering Laboratory in Toulouse and obtained her Ph.D. degree in electrical engineering in 2004 from Paul Sabatier University. She entered the CNRS (National Centre of Scientific Research) in 2006. She is now dealing with modelling activities in relation with charge transport and ageing, for various domains of applications like electrical engineering, spatial environment. She is also concerned in the relationship between experiments and simulations.

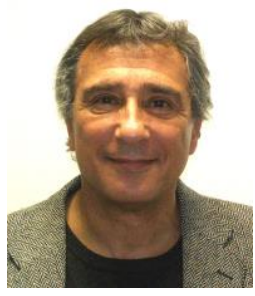

Christian Laurent (M'98-SM'07) was born in Limoges, France, in 1953. He studied solid state physics at the National Institute for Applied 
Sciences in Toulouse and received his Eng. degree in physics in 1976. He joined the Electrical Engineering Laboratory at Paul Sabatier University in 1977 to study electrical treeing and partial discharge phenomena, which were the topics of his Dr. Eng. degree (1979). He joined CNRS (National Centre for Scientific Research) in 1981 and got his Doc-ès Sc. Phys. in 1984. In 1985, he spent one year as a post-doctoral fellow with the IBM "Almaden Research Center" where he studied plasma-polymerized thin films. Back in Toulouse he developed an approach to electrical ageing in polymeric materials based on luminescence analysis. He is now dealing with experimental and modeling activity relating to charge transport and ageing. He is currently Research Director at CNRS and was until recently Director of the Laboratory of Plasma and Energy Conversion -LAPLACE- in Toulouse. 